\title{
Sex and Relationship Differences on the Short Love Attitude Scale: Insights from the Hungarian Adaptation
}

\author{
Norbert Meskó ${ }^{1}$ (D) András N. Zsidó ${ }^{1} \cdot$ András Láng $^{2} \cdot$ Kázmér Karádi $^{3}$
}

Accepted: 9 February 2021 / Published online: 1 March 2021

(c) The Author(s) 2021

\begin{abstract}
Love styles are attitudes towards romantic relationships that are related to sexual motivation, sociosexuality, mate value, and relationship status. In the present study, the Short Love Attitude Scale (LAS-SF) was adapted to Hungarian, and the original factor structure was replicated with a Hungarian sample of 800 participants (439 females, mean age $=38.6$ years). The results show that the Hungarian LAS-SF is a reliable and valid measure, which enables cross-cultural comparisons. Differences in love styles were revealed across sexes and relationship statuses. All men except singles scored relatively high on Eros, while the highest Eros scores among women were obtained for those in a committed relationship. Women and men preferred the same strategy (Ludus) to achieve short-term relationship goals.
\end{abstract}

Keywords Love attitude scale $\cdot$ Sex differences $\cdot$ Relationship status $\cdot$ Hungarian version

\section{Introduction}

\section{Love Attitudes}

In an earlier work, Lee (1973) used the analogy of a colour wheel to illustrate his typology of love. This model comprises three "primary colours", that is, three primary love types such as Eros (passionate, romantic love), Ludus (playful, uncommitted love), and Storge (friendly love). Secondary love types are defined as

Norbert Meskó

meskonorbert@me.com

1 Department for General and Evolutionary Psychology, Institute of Psychology, University of Pecs, Pécs, Hungary

2 Department for Developmental and Clinical Psychology, Institute of Psychology, University of Pecs, Pécs, Hungary

3 Department of Behavioural Sciences, Divison of Clinical Behavioural Sciences, University of Pecs, Pécs, Hungary 
balanced mixtures of the three primary types: Pragma (practical, rational love) is a combination of Storge and Ludus, Mania (obsessive or addictive love) is a combination of Eros and Ludus, and Agape (altruistic or unselfish love) is a combination of Eros and Storge. Thus, the model defines six different love types, which are used to describe individual differences in love (e.g., Raffagnino and Puddu 2018). This typology provides a relatively complex and comprehensive classification, which is consistent with everyday experience and language (Hendrick and Hendrick 2006).

Following the model proposed by Lee $(1973,1988)$, some researchers made efforts to develop a measuring instrument enabling them to verify the validity of the theory and to explore the relationship between various love styles and other variables (e.g., personality traits; Laswell and Laswell 1976). The instrument became eventually known as the Love Attitudes Scale (LAS; Hendrick and Hendrick 1986; 1990). During the analysis process six love style scales emerged clearly from factor analysis and later replicated the factor structure, factor loadings, and reliability. Internal reliability was shown for each scale, and the scales had low intercorrelations with each other. The significant relationships between love attitudes and sex, previous love experiences, current love status, and self-esteem. Subsequently, the original LAS questionnaire was used in a number of studies (e.g. Bailey et al. 1987; Hendrick and Hendrick 1990; Hendrick 1988; Hendrick and Adler 1988; White et al. 2004). A short version of the LAS was also developed subsequently, whose 24 items showed better psychometric properties than the original full version (Hendrick and Dicke 1998). This means that increased inter-item correlations (compare to the 7-item subscales) maintained the strength of the alphas, despite subscale length was reduce from seven to four items.

In addition to the development of different versions of the LAS, critical voices also emerged that considered the results of the questionnaire with confirmatory factor analysis unacceptable (Rotzien et al. 1994).

Another line of research has found biological evidence for the basic premise of human love styles. Emanuele at al. (2007) found a significant association between the DRD2 TaqI A genotypes and Eros, as well as between the C516T 5HT2A polymorphism and Mania. These associations were present in both sexes and remained significant even after adjustment for potential confounders. This means that the functioning of the human neuroendocrinological system is related to the type of love individual experiences: different neurotransmitter genes are activated in different love styles.

Over recent years, the scale has been adapted for, and used in, various cultures including Chinese (Yang and Liu 2007), Malaysian (Wan Shahrazad et al. 2012), Turkish (Bugay and Tezer 2008), Italian (Agus et al. 2018), Portuguese (Neto 1993), and French samples (Neto et al. 2000).

\section{Sociosexuality}

The term sociosexuality was originally used to describe the diversity of sexual behavior in men and women. (Jonason 2019). Simpson and Gangestad (1991) initially developed a measure of individual differences in attitudes and behavior 
towards casual sex, while Penke and Asendorpf (2008) added sociosexual desire to the original construct and measure. According to Jackson and Kirkpatrick (2007), sociosexuality comprises short-term and long-term mating interest, and past sexual behavior. Existing empirical findings on the psychological contexts of sociosexuality suggest that men are more willing to engage in casual sex than women, which applies globally (Lippa 2009; Schmitt, 2005). Furthermore, unrestricted socio-sexuality is associated with maximizing mating efforts, while restricted sociosexuality is more closely associated with parental efforts (Valentova et al. 2020). Finally, unrestricted sociosexuality is positively correlated with openness to casual sex among users of online dating sites (Hallam et al. 2018). However, one study concludes that unrestricted sociosexuality predisposes to extradic casual sex only when accompanied by a low level of commitment to a long-term partner (Rodrigues and Lopes 2017).

Neto (2015; see also Marzec and Łukasik 2017) found that sociosexuality was negatively associated with Eros among both men and women (overall $=-0.21$, $p<0.001$; men $=-0.23,<0.001$; women $=-0.21,<0.01)$. This suggests that individuals restricted in sociosexuality are more likely to pursue erotic love as compared to unrestricted ones. Those characterized by Eros prefer strong physical attraction, emotional intensity, a popular physical appearance, and a sense of inescapability of the relationship (Hendrick and Hendrick 2006). Another central feature of this style is the preference for relatively close and exclusive love relationships. Furthermore Neto (2015) found also sex differences in the strengths of associations between sociosexuality and love styles. The difference between males' and females' correlations on Ludus ( $p<0.001)$, Pragma $(p<0.001)$, Mania $(p<0.001)$, Agape $(p<0.05)$.

\section{Love, Sex, and Life History Theory}

Frey and Hojjat (1998) explored measurable associations between love attitudes and preferences for various sexual scripts. They found that all love attitudes correlated positively with a preference for commitment except Ludus, with which commitment showed a negative correlation. These results were corroborated by subsequent findings that revealed a positive association between a game-playing love style (Ludus) and unrestricted sociosexual orientation (e.g., Jonason and Kavanagh 2010; Lee et al. 2013; Proyer et al. 2018; Smith et al. 2019).

According to the Life History Theory (Belsky et al. 1991; Kaplan et al. 2005) behavioral adaptation to various environmental (ecological and/or social) conditions encountered during childhood is regulated by a wide variety of different traits resulting in various behavioral strategies (see Csathó and Birkás, 2018). LH strategies are resource allocation patterns including trade-offs configured to adjust resource utilization to local conditions and to optimize adaptive behavior such as mating or parental investment (Bjorklund and Ellis 2014; Ellis et al. 2009). These resource expenditure sequences may be positioned on a dimension of slow to fast strategies (Del Guidice et al. 2015). Slow LH strategies are characterized by the ability to delay gratification, future/long-term focused behavioral strategies, and better 
quality of parental care (i.e., larger investment of time and effort in each offspring). By contrast, individuals with faster LH strategies possess a more present/short-term oriented attitude including opportunistic, impulsive and self-beneficial behaviors, higher frequency of mating with an early start, and little investment in social relationships and in the offspring (Griskevicius et al. 2011; Nettle 2010).

Some of the more recent studies suggest that the relationship between love and sexuality essentially depends on the quality of the partners' relationship, which is interpreted in a biological-evolutionary framework. Findings reported by Marzec and Łukasik (2017) showed that the Ludus love style was associated with a fast life history (LH) strategy while Eros with a slow LH strategy. LH strategies are resource allocation patterns including trade-offs configured to adjust resource utilization to local conditions and to optimize adaptive behavior such as mating or parental investment (Bjorklund and Ellis 2014; Ellis et al. 2009; Kaplan and Gangestad 2005). These resource expenditure sequences may be positioned on a dimension of slow to fast strategies (Del Guidice et al. 2015). Slow LH strategies are characterized by the ability to delay gratification, future/long-term focused behavioral strategies, and better quality of parental care (i.e., larger investment of time and effort in each offspring). By contrast, individuals with faster LH strategies possess a more present/ short-term oriented attitude including opportunistic, impulsive and self-beneficial behaviors, higher frequency of mating with an early start, and little investment in social relationships and in the offspring (Griskevicius et al. 2011; Nettle 2010; Belsky et al. 1991).

From the perspective of the Life History Theory, the Ludus love style is part of a fundamentally goal-directed mating strategy focused on opportunities of maximizing resources (Marzec and Łukasik 2017). This means that although Ludus cannot be equated with one-on-one short-term relationship and sexual functioning, it can still be said to be an emotional component of the same mating strategy.

\section{Sexual Motivation}

Sexual motives have been described as the conscious and subjective reasons stated by men and women for engaging in sexual activity (e.g. Hatfield et al. 2012; Meston and Buss 2007; Meston and Stanton 2017). Sexual activity is influenced by a number of biopsychosocial factors as well as by contextual factors of the relationship such as the type and/or duration of the relationship, and partners' attachment style (Meston and Stanton 2017). Several studies revealed sex differences in sexual motivation (e.g., Meston and Buss 2007; Meston et al. 2009,2019), which show that women primarily have relationship-related reasons as opposed to men who are more likely to report self-focused reasons. Armstrong and Reissing (2015) explored the effects of relationship type on sexual motivation. Their results revealed that physical motives were more pronounced in those preferring casual sexual relationships, whereas those having a committed relationship showed stronger emotional motives. Engaging in casual sex does not require an emotional attachment, since partners are not motivated to commit themselves to each other in a long-term relationship and reap the benefits of commitment. Meskó et al. (2019) developed the Hungarian 
Short Form of the Reasons for Having Sex Questionnaire (YSEX?-HSF) which revealed marked sex and age differences in sexual motivation. The YSEX?-HSF showed a factor structure different from that of the original American version of the questionnaire (Meston and Buss 2007): the former is composed of three primary factors comprising 24 subfactors; the latter consists of four primary factors and 13 subfactors. Despite the differences between factor structures, the composition of reasons for having sex are highly similar in the two factors. This finding points to both the cross-cultural universality of human sexual motivation, and also the cultural diversity reflected in the differences between the two factor structures. Initial results with the YSEX?-HSF indicated, that self-centered and stress-related motives for sex were positively associated with unrestricted sociosexuality.

\section{Sex Differences}

Studies on romantic love and sexuality frequently raise the issue of sex differences in love styles (for a review, see, e.g., Raffagnino and Puddu 2018; Zeigler-Hill 2015). Existing findings suggest that men $(N=444)$ tend to have higher levels of Ludus than women $(N=646)$ (2.64 vs. $2.12 ; p<0.001 ; \mathrm{F}=98.51)$ while women report higher levels of Mania (3.10 vs. 2.94; $p<0.01 ; \mathrm{F}=8.98$ ), Storge (3.69 vs. 3.42; $p<0.001 ; \mathrm{F}=23.49)$ and Pragma (2.96 vs. 2.71; $p<0.001 ; \mathrm{F}=17.78)$ than men (e.g., Hendrick and Hendrick 1995). Hendrick (1984) found that women were more pragmatic, storgic, and manic in their love attitudes, while men's love styles tended to be more erotic and ludic. This means that men tend to hold romantic beliefs and attitudes that are consistent with eroticism and playfulness. By contrast, women are more likely to build relationships based on practical love and a sense of despair. These sexually divergent love patterns are generally consistent with the sex differences found by researchers in the mating context. For example, it is known from previous research that men are more likely than women to consider engaging in shortterm sexual encounters (e.g., Clark and Hatfield 1989), while women are more likely to regret casual sex if they do participate at all (Kennair 2018). Another marked sex difference is that women often tend to be somewhat more selective than men when considering partners for various types of romantic relationships (e.g., Buss and Schmitt 2019). Sex differences in love, mate preferences and sexuality reflect, on one hand, the social structures that influence male and female sexual behavior (e.g., Eagly and Wood 1999), and, on the other hand, well demonstrate the fundamental psychological characteristics of sexual psychology of men and women (Ohno 1967; Walsh 1993), which is thought to be the result of differences in physical reproductive mechanisms and parental investment (Trivers 1972).

\section{Mate Value}

One's mate value is an indicator informing potential partners about one's inclusive fitness in a mate choice context (Howie and Pomanowski, 2018). Broadly speaking, one's mate value is one's attractiveness as perceived by potential partners of the opposite sex. Mate value is based on a set of characteristics such as, for example, 
fertility, intelligence, social status, access to resources, and willingness to make parental investments (e.g., Buss 1989; Kirsner et al. 2003). The relevant indicators of mate value show considerable sex differences. Men assign relatively high priority to potential female partners' young age and fertility, while women tend to focus on men's social status, intelligence, access to resources, and willingness to make parental investments (e.g., Buss 2006; Buss and Schmitt 1993; 2019; Conroy-Beam et al. 2019; Walter et al. 2020). As a result of these differences in the perception of mate value indicators, the mate value possessed by different individuals also shows considerable variety. Those having a higher mate value are less restricted in pursuing and optimizing their sexual strategy (e.g., Rhodes 2005; Simpson and Gangestad, 1992). In fact, a positive relationship was found between physical attractiveness and the number of sexual partners irrespective of participants' sex (e.g., Thornhill and Gangestad 1994). Thus, mate value has an impact on the availability and optimizability of various sexual strategies and thereby on reproductive fitness. Several selfreport measures of mate value have been developed (e.g., Edlund and Sagarin 2014; Fletcher 1999; Kirsner 2003), whose items partly overlap, albeit being based on different theoretical conceptualizations. In a recent study, Gillen et al. (2016) revealed positive correlations between mate value of the respondent's partner (this had to be assessed by the respondent) and the respondent's self-reported love style, although significant (low or medium) correlations were found only in Eros and Pragma. To the knowledge of the authors, there is no research aimed at exploring the relationships between love styles and mate value.

\section{Relationship Status and Age Differences}

Previous cross-sectional studies found that various relationship statuses were associated with different love styles. Richardson (1988) revealed that participants currently involved in an intimate partner relationship scored higher on the Eros love style than those who reported on a past or anticipated relationship. Furthermore, those who completed self-report measures in the context of a past relationship scored higher on Mania than those who reported on an anticipated relationship. Only marginal effects were obtained for Ludus, which might be the case in part because the authors did not assess short-term relationship statuses (e.g., one-night stand, casual sex, fling) in addition to the distinction between current, past and anticipated relationships. In an earlier study, which included an assessment of participants' preference for shortterm relationships, Morrow (1995) found that casual daters and married individuals scored significantly lower on Eros than those who were dating regularly, cohabiting or engaged, irrespective of participants' sex. Furthermore, female casual daters were more likely to endorse Ludus than women who were dating regularly or engaged.

These findings point to the methodological importance of assessing participants' preference for short-term relationships in studies focusing on the associations between relationship statuses and love styles. In the 1980s and before, researchers probably followed moral considerations when choosing not to include shortterm relationship statuses in the available response alternatives. Subsequent studies assessed dating frequency (casual vs. regular dating; e.g. Morrow et al. 1995), 
which, however, did not enable researchers to make a distinction between currently single participants and those preferring casual sexual relationships. Researchers adopting a different methodological approach assessed the duration of participants' relationships (e.g., Ahmetoglu et al. 2010). While duration may indeed be positively associated with the depth of a relationship, it does not necessarily reflect the level of commitment. Hadden et al. (2019) point out that the more seriously partners take their relationship, the more committed and satisfied they are, and the larger emotional and/or material investments they are willing to make.

Previous research on love styles generally did not address possible age differences (e.g., Davies 1996; Frey and Hojjat 1998; Gana 2013; Lacey et al. 2004; Neto 2015; Neto et al. 2000). Not even a meta-analysis encompassing 22 studies (including other meta-analyses) found any empirical results on the relationship between age and love styles (Raffagnino and Puddu 2018). Nevertheless, preferences for various love styles are very likely to develop and change over time, and therefore they probably vary with age, but this relationship may not be reliably assessed in a cross-sectional design. Instead, the subject requires longitudinal studies enabling researchers to reveal the effects of maturation and behavioral development in intimate partner relationships as pointed out by Hammock and Richardson (2011).

The primary aim of the present study was to develop and validate the Hungarian version of the Short Love Attitude Scale. A secondary aim of the study was to replicate the original factor structure with a Hungarian sample. To obtain cross-culturally comparable data, the same scales were used for psychometric analysis as those used in the development of the original LAS-SF and its various national versions. The third aim of our study is to find a relationship between love styles and age, and between love styles and relationship status.

\section{Hypothesis, Predictions, and Research Aims}

Hypothesis As the Love Attitude Scale is a research tool in which the six factors are not the result of a traditional test development procedure, but are based on Lee's theory, we assume that the primary goal of the Hungarian adaptation is to verify this theoretically grounded, original factor structure. The Hungarian adaptation of LASSF (LAS-HSF) was expected to show adequate psychometric properties and validity, similarly to the original version and its previously published adaptations (Agus et al. 2018; Bugay and Tezer 2008; Hendrick and Dicke 1998; Neto 1993; Neto et al. 2000; Wan Shahrazad et al. 2012; Yang and Liu 2007).

Prediction 1-Reliability The LAS-HSF was expected to show good psychometric properties and a factor structure identical with that of the original version (Hendrick and Dicke 1998).

Prediction 2-Validity The love style measures were expected to show associations with sociosexuality, sexual motivation and mate value consistent with those obtained in previous studies (see, respectively, Neto 2015; Armstrong and Reissing 2015; Zeigler-Hill et al. 2015). We predict that sociosexuality is negatively correlated with Eros (Neto 2015). In other words, individuals more open to casual 
contact (more unrestricted sociosexuality) report lower Eros scores. To the best of our knowledge, the relationships between sexual motivation and love attitudes have not been studied before. Therefore, we can only base it on the results of research that has partly asked similar questions (Armstrong and Reissing 2015; Meskó et al 2019). Based on the negative correlation between self-esteem and Mania (ZeiglerHill et al. 2015), we expected Mania to be negatively correlated with self-perceived mate value.

Research aim In consistence with the above discussed theoretical considerations, participants' preferences for various love styles were expected to vary with their relationship status (e.g., single, engaging in casual sexual relationships, living in a committed relationship, married). From a broader theoretical perspective, one's love style (i.e., the specific pattern of cognitive, affective and behavioral components of one's attitude towards one's sexual partner) was hypothesized to be part of one's underlying mate choice strategy, whose manifestation was expected to vary with sex (e.g., Eagly and Wood 1999; Ellis 1992; Naftolin 1981), age (e.g., Fawcett and Johnstone 2003), and relationship status (e.g., Buss 1989; Conroy-Beam et al. 2019; Walter et al. 2020). This part of the study is explicitly exploratory, thus, no predictions were formulated.

\section{Method}

\section{Procedure and Participants}

The authors first translated the items of, and instructions for, the LAS-SF into Hungarian, and the obtained Hungarian version was verified with the standard backtranslation technique (Brislin 1980). Specifically, the items and instructions were retranslated into English by an independent translator unaffiliated with the study, and the two translators then resolved minor discrepancies that emerged during the back-translation procedure.

The sample included 800 voluntary participants (361 males and 439 females) aged 18 to 69 years $(M=38.6, S D=12.5)$. According to the reported relationship statuses, 120 participants were single, 60 had casual sexual relationships (or flings), 176 were involved in a committed relationship, and 444 were married. Data were collected online. The survey was edited in Google Forms. The link to the survey was disseminated via Facebook and via one of the most popular and influential Hungarian internet portals, Index (https://index.hu/). All participants gave informed consent, and none of them was rewarded for participation. The study received ethical approval as part of a larger research project on mating strategies from the Hungarian United Ethical Review Committee for Research in Psychology (Ref. No. 2018/115).

\section{Measures}

Love Attitudes Scale, Short Form (LAS-SF; Hendrick and Dicke 1998). The LAS-SF contains 24 items, which compose the following six subscales: Eros (erotic, romantic, 
passionate love style), Ludus (game-playing love style), Storge (affectionate, friendship-oriented love style), Pragma (rational, shopping-list love style), Mania (possessive, dependent love style), and Agape (selfless love style). Each subscale has four Likert items, and respondents indicate the extent to which each item applies to them on a 5-point rating scale ranging from 1 (strongly disagree) to 5 (strongly agree). Thus, higher scores reflect higher preference for the specific love style. Detailed data on the internal consistency of the scale are presented in the Results section.

Sociosexual Orientation Inventory, Revised (SOI-R; Penke and Asendorpf 2008; adapted to Hungarian by Meskó et al. 2014). The SOI-R comprises nine items assessing one's willingness to engage in uncommitted sexual encounters. The items compose three subscales measuring the three components of behavior, attitude and desire. Responses are given on 9-point rating scales (scale anchors vary across items). Higher scores on each subscale indicate more unrestricted sociosexuality in terms of behavior, attitude and/or desire. Cronbach's $\alpha$ values for the three subscales and the overall scale were as follows: Behavior: 0.87; Attitude: 0.83; Desire: 0.90; SOI-R (overall): 0.88 .

Reasons for Having Sex Questionnaire, Hungarian Short Form (YSEX?-HSF; Meskó et al. 2019). The YSEX-HSF is a self-report instrument similar to the original questionnaire in item composition and slightly different in factor structure which characteristics support both, the cross-cultural universality of human sexual motivation and also the cultural diversity (reflected in the differences of the factor structure). The questionnaire comprises 73 items, which compose the following three scales: Personal goal attainment, Relational reasons, Sex as coping. This differs from the original YSEX? (Meston and Buss 2007) four scales questionnaire. Each item is rated on a 5-point scale offering the following options: $1=$ "None of my sexual experiences"; 2 = "Few (...)"; 3 = "Some (...)"; 4 = "Many (...)"; 5 = "All of my sexual experiences". Thus, higher scores reflect higher levels of the measured sexual motive. Cronbach's $\alpha$ values for the three scales were as follows: Personal goal attainment: 0.91; Relational reasons: 0.92; Sex as coping: 0.91.

Mate Value Scale (MVS; Edlund and Sagarin 2014; adapted to Hungarian by Csajbók et al. 2019). The MVS is a self-report measure assessing one's own value as a mate. Its four items show a unifactorial structure, it has good internal consistency and test-retest reliability as well as adequate convergent and discriminant validity. Each item is rated on a 7-point scale ranging from (1) extremely undesirable to (7) extremely desirable on two items, from (1) very much lower than average to (7) very much higher than average on one item, and from (1) a very bad catch to (7) a very good catch on one item. Cronbach's $\alpha$ for the MVS in the present study was 0.88 .

Relationship status. The assessment of participants' relationship status followed the method used by Dush and Amato (2005) in that participants did not indicate the duration of their current relationship, but they defined their relationship status in terms of commitment to the partner (single, casual relationship, committed cohabitation, marriage). 


\section{Data Analysis}

A confirmatory factor analysis (CFA) was run on the items of the LAS-HSF to test whether the original six-factor model would show the best fit indices. Cronbach's $\alpha$ coefficients were calculated for the subscales to assess their internal consistency. ${ }^{1}$

Construct validity is the degree to which a test measures what it claims or purports to measure. It can be obtained in two ways: either by using special groups that the questionnaire should be able to differentiate between or by a statistical analysis of the relationship between two measures. We used relationship status as a grouping variable to examine whether the LAS-HSF subscales they would differentiate between participants with different relationship statuses. Convergent and discriminant validity are subtypes of construct validity. Providing evidence for both convergent and discriminant validity means by definition that evidence for construct validity has been given (Cronbach \& Meehl, 1955). Convergent validity was tested with an analysis of correlations between the LAS-SF subscales and the YSEX?-HSF and SOI-R subscales, while the MVS was used to examine discriminant validity. Due to the number of correlations, correction for multiple comparisons seemed necessary. For this purpose, we used Bonferroni correction (the new alpha was 0.001).

Sex differences were examined with independent samples $t$-tests, while the possible effects of age were tested with correlation analyses. Possible interactions between sex and relationship status were examined with two-way ANOVAs. Where the interaction was nonsignificant, one-way ANOVAs were used to examine relationship status differences. The skewness and kurtosis values for the dependent variables in these analyses were between -2 and +2 , and thus, can be considered acceptable in order to prove normal univariate distribution (Field 2000 and 2009; Gravetter and Wallnau 2014; Trochim and Donnelly 2006). Nevertheless, we also used nonparametric tests (i.e., Kruskal-Wallis and Mann-Whitney tests) to confirm the results. The results of these tests matched those of the parametric tests, therefore only the former results are presented below. The statistical analyses were conducted with the JAMOVI v. 1.0 for Windows (The Jamovi Project, 2020) application.

\footnotetext{
1 We also used the graded response model (GRM) (Samejima 1968) to examine the psychometric properties of each item. The GRM allows items to relate differentially to a latent trait, thus the GRM estimates item discrimination (a) and difficulty (b) parameters. The a parameter shows the scale slope at a given item location, i.e. b parameter, where the discrimination occurs. The steeper a slope is the better discrimination property an item has (Baker 2001). The discrimination power of an item is moderate if the a parameter is between the values .65 and 1.34, high if the value falls between 1.35 and 1.69 and can be considered very high is it is above 1.70 (Baker 2001). The estimated category difficulty, i.e. b parameter, represent a point at which a person with ability equal to a given difficulty has a $50 \%$ chance of responding in a category equal to or higher than the difficulty designates. The analysis showed that all items had at least moderate discrimination power (the majority had high or very high). See Supplementary Table 1 for the coefficients, standard errors and $95 \%$ confidence intervals.
} 
Table 1 Mean scores, medians, and standard deviations of the six subscales of the LAS-HSF broken down by gender

\begin{tabular}{llllllll}
\hline & Gender & Eros & Ludus & Storge & Pragma & Mania & Agape \\
\hline \multirow{2}{*}{ Mean } & Male & 15.20 & 10.90 & 8.81 & 7.61 & 8.98 & 11.70 \\
& Female & 16.40 & 8.08 & 9.49 & 8.84 & 9.63 & 11.10 \\
\multirow{5}{*}{ Median } & Male & 16 & 11 & 8 & 7 & 9 & 12 \\
& Female & 17 & 7 & 8 & 8 & 9 & 11 \\
Std. Dev & Male & 3.63 & 4.35 & 4.31 & 3.08 & 3.61 & 3.82 \\
& Female & 3.26 & 3.96 & 4.83 & 3.64 & 3.96 & 3.95 \\
\hline
\end{tabular}

\section{Results}

\section{Reliability of the LAS-HSF}

The CFA indicated that the original six-factor model provided an excellent fit $(\mathrm{CFI}=0.946, \mathrm{TLI}=0.936$, RMSEA $=0.045$ [90\% CI: 0.041-0.049], SRMR $=0.043$ ) on our sample. Descriptive data and the mean scores of the sample are also presented in Table 1. All six subscales showed good internal consistency. The fit indices of the model with covariances indicated an excellent fit of the model to our data (see Fig. 1). Cronbach's alpha value was 0.82 for the Eros subscale, 0.77 for the Ludus subscale, 0.87 for the Storge subscale, 0.64 for the Pragma subscale, 0.73 for the Mania subscale and 0.83 for the Agape subscale.

\section{Validity of the LAS-HSF}

For better transparency all correlational results will be presented in Table 2 and not in-text. The subscales and total score of the SOI-R showed positive moderate correlations with the Ludus subscale and moderate negative with the Eros subscale, while weak negative correlations with the Storge, Mania and Agape subscales of the LAS-SF. Furthermore, with regard to the YSEX?-HSF questionnaire, sex as coping showed weak positive correlation with Ludus and Mania love styles, while personal goal attainment showed a moderate to strong positive correlation with the Ludus love style. Contrary to our expectations the MVS did not correlate with Mania subscale of the LAS-SF and showed only very weak correlations with Eros, Pragma and Agape.

\section{Sex and Age Differences}

We found sex differences across all six subscales with females scoring higher compared to males on the Eros subscale with a mean difference of 1.22 (95\% $\mathrm{CI}=0.74-1.69, \mathrm{t}(798)=4.99, p<0.001$, Cohen's $\mathrm{d}=0.35)$, Storge subscale with a mean difference of $0.68(95 \% \mathrm{CI}=0.03-1.32, \mathrm{t}(798)=2.06, p=0.039$, Cohen's $\mathrm{d}=0.15)$, Pragma subscale with a mean difference of $1.23(95 \% \mathrm{CI}=0.76-1.70$, $\mathrm{t}(798)=5.09, p<0.001$, Cohen's $\mathrm{d}=0.36)$, Mania subscale with a mean difference of 0.65 (95\% CI $=0.12-1.18, \mathrm{t}(798)=2.40, p=0.017$, Cohen's $\mathrm{d}=0.17$ ). Males scored higher compared to females on the Ludus subscale with a mean difference 


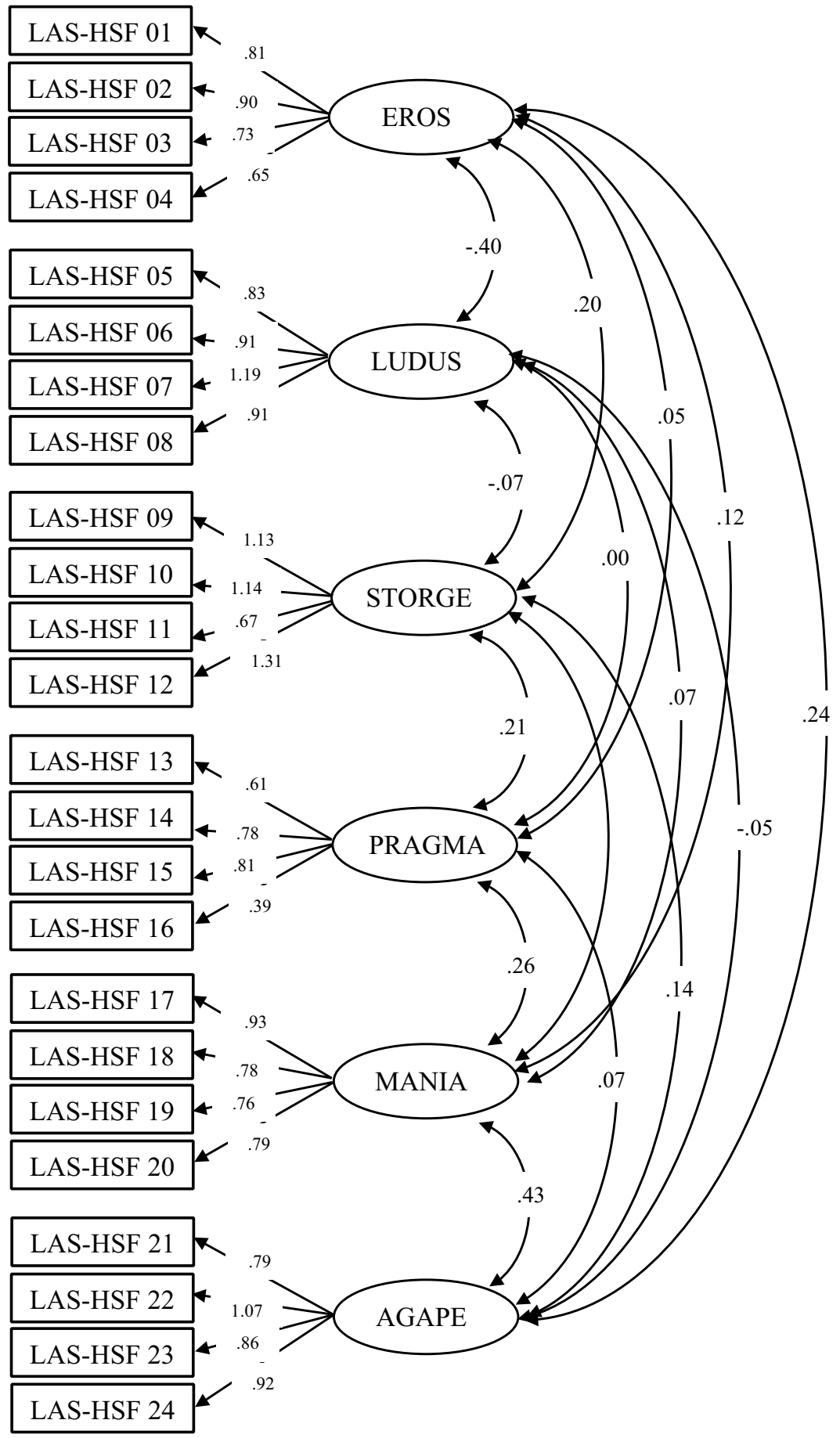

Fig. 1 Standardized six-factor structure of the Hungarian Short Love Attitude Scale (LAS-HSF) model 
Table 2 Correlations of the six subscales of the LAS-HSF with the three subscales and the total score of the Revised Sociosexual Orientation Inventory (SOI-R), with the total score of the Mate Value Survey (MVS), and with the three scales of the Hungarian Short Form of the Reasons for Having Sex Questionnaire (YSEX?-HSF)

\begin{tabular}{|c|c|c|c|c|c|c|}
\hline & Eros & Ludus & Storge & Pragma & Mania & Agape \\
\hline SOI Behavior & $-.169 * * *$ & $.467 * * *$ & $-.140 * * *$ & -.032 & -.066 & $-.134 * * *$ \\
\hline SOI Attitude & $-.166 * * *$ & $.426 * * *$ & $-.120 * * *$ & $-.108 * *$ & $-.118 * * *$ & $-.136^{* * *}$ \\
\hline SOI Desire & $-.300 * * *$ & $.497 * * *$ & -.057 & .009 & .026 & -.058 \\
\hline SOI Total & $-.265^{* * *}$ & $.566^{* * *}$ & $-.118^{* * *}$ & -.056 & -.057 & $-.127 * * *$ \\
\hline MVS Total & $.151 * * *$ & $.083^{*}$ & -.004 & $.142 * * *$ & -.052 & $-.128 * * *$ \\
\hline YSEX Personal Goal Attainment & $-.190 * * *$ & $.541 * * *$ & -.056 & $.100 * *$ & $.124 * * *$ & -.037 \\
\hline YSEX Relational Reasons & $.108 * *$ & $.125^{* * *}$ & $.085^{*}$ & $.180 * * *$ & $.187 * * *$ & $.127 * * *$ \\
\hline YSEY Sex as Coping & $-.169 * * *$ & $.282 * * *$ & -.015 & $.192 * * *$ & $.291 * * *$ & $.073 *$ \\
\hline
\end{tabular}

${ }^{*} p<.05,{ }^{* *} p<.01,{ }^{* * *} p<.001$

According to the Bonferroni correction for multiple comparisons, the new alpha is .001, thus only $* * *$ results can be viewed as statistically significant

of $2.86(95 \% \mathrm{CI}=2.28-3.44, \mathrm{t}(798)=9.74, p<0.001$, Cohen's $\mathrm{d}=0.69)$ and Agape subscale with a mean difference of $0.57(95 \% \mathrm{CI}=0.03-1.11, \mathrm{t}(798)=2.06$, $p=0.039$, Cohen's $\mathrm{d}=0.15$ ).

We also found sex differences on the total score and three subscales of SOI with males compared to females scored higher in every case. For total score the mean difference was $14.29(95 \% \mathrm{CI}=12.22-16.36, \mathrm{t}(798)=13.33, p<0.001$, Cohen's $d=0.96)$, for the Behavior subscale the mean difference was $3.57(95 \%$ $\mathrm{CI}=2.69-4.46, \mathrm{t}(798)=7.95, p<0.001$, Cohen's $\mathrm{d}=0.57)$, for the Attitude subscale the mean difference was $4.31(95 \% \mathrm{CI}=3.42-5.20$, $\mathrm{t}(798)=9.49, p<0.001$, Cohen's $d=0.67)$, and for the Desire subscale the mean difference was $6.40(95 \%$ $\mathrm{CI}=5.55-7.25, \mathrm{t}(798)=14.79, p<0.001$, Cohen's $\mathrm{d}=1.05)$. Females scored higher on MVS compared to males with a mean difference of 1.18 (95\% CI $=0.62-1.74$, $\mathrm{t}(798)=4.13, p<0.001$, Cohen's $\mathrm{d}=0.29)$. Further, males scored higher on the Personal Goal Attainment of YSEX with a mean score of 6.89 (95\% CI =4.72-9.06, $\mathrm{t}(798)=6.24, p<0.001$, Cohen's $\mathrm{d}=0.44)$. However, on the Sex as Coping subscales females scored higher than males with a mean score of 1.01 (95\% CI $=0.95-4.92$, $\mathrm{t}(798)=2.91, p=0.004$, Cohen's $\mathrm{d}=0.21)$. We found no difference between males and females on the Relationship Reasons subscale of YSEX.

Regarding the relationship of age and LAS-HSF subscales, the Spearman correlation showed rather weak relationship across four of the six subscales: Eros (rho $=-0.19, p<0.01)$, Ludus $($ rho $=0.27, p<0.01)$, Storge $\quad($ rho $=-0.06$, $\mathrm{p}=0.086$ ), Pragma (rho $=-0.13, p<0.01)$, Mania (rho $=-0.08, p=0.028)$ and Agape (rho $=-0.04, p=0.29$ ).

\section{Relationship Status}

The interaction between relationship status and sex was significant for the Eros $\left(\mathrm{F}(3,792)=2.87, p=0.036, \eta_{p}{ }^{2}=0.01\right)$ and the Ludus $(\mathrm{F}(3,792)=3.46, p=0.016$, 

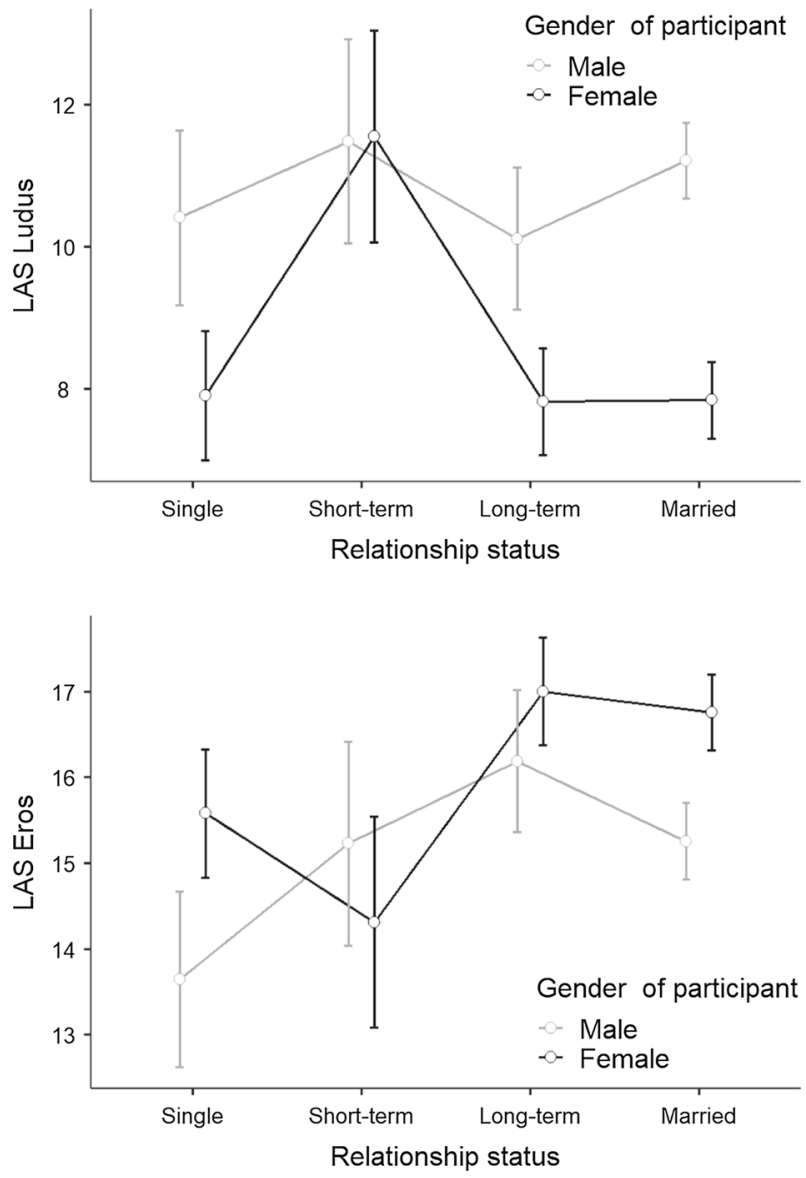

Fig. 2 Relationship status (single, short-term, long-term, married) $\times$ gender (males, females) interaction effects on the Eros (bottom) and Ludus (top) subscales of the LAS-HSF. Raw scores are presented with $95 \%$ confidence intervals

$\left.\eta_{p}{ }^{2}=0.01\right)$ subscales. The interaction on the other four subscales were nonsignificant (Fs $<1$, ps $>0.1$ ). For the Eros subscale, follow-up one-way ANOVAs revealed different patterns for the relationship status. In males $(\mathrm{F}(3,357)=4.27, p=0.006$, $\left.\eta_{p}{ }^{2}=0.035\right)$, Tukey-corrected post-hoc analyses showed that single participants scored lower then those in a long-term relationship $(\mathrm{t}(357)=3.58, p=0.002)$ or married $(\mathrm{t}(357)=2.68, p=0.039)$. The other groups did not differ from each other significantly. In contrast, in females $\left(\mathrm{F}(3,435)=8.10, p<0.001, \eta_{p}{ }^{2}=0.05\right)$, single and short-term groups had a lower score than long-term $(\mathrm{t}(435)=3.03, p=0.014$; $\mathrm{t}(435)=4.05, \quad p<0.01, \quad$ respectively) and married $(\mathrm{t}(435)=2.81, \quad p=0.027$; $\mathrm{t}(435)=3.89, p<0.01$, respectively) groups. There were no other significant group differences. For the Ludus subscale, follow-up one-way ANOVAs revealed different patterns for the relationship status. The main effect was nonsignificant in males. 
Table 3 Mean scores and 95\% confidence limits of the six subscales of the LAS-HSF broken down by gender and relationship status

\begin{tabular}{|c|c|c|c|c|c|}
\hline \multirow[t]{2}{*}{ Gender } & \multirow[t]{2}{*}{ Relationship status } & \multirow[t]{2}{*}{ LAS-SF subscale } & \multirow[t]{2}{*}{ Mean } & \multirow{2}{*}{$\begin{array}{l}95 \% \text { Confidence } \\
\text { Interval } \\
\text { Lower }\end{array}$} & \multirow[b]{2}{*}{ Upper } \\
\hline & & & & & \\
\hline \multirow[t]{24}{*}{ Male } & \multirow[t]{6}{*}{ Single } & Eros & 13.67 & 12.51 & 14.82 \\
\hline & & Ludus & 10.43 & 9.27 & 11.58 \\
\hline & & Storage & 9.19 & 8.03 & 10.35 \\
\hline & & Pragma & 7.78 & 6.63 & 8.94 \\
\hline & & Mania & 9.71 & 8.56 & 10.87 \\
\hline & & Agape & 12.00 & 10.84 & 13.16 \\
\hline & \multirow[t]{6}{*}{ Short-term } & Eros & 15.25 & 13.91 & 16.59 \\
\hline & & Ludus & 11.51 & 10.17 & 12.85 \\
\hline & & Storage & 7.86 & 6.52 & 9.20 \\
\hline & & Pragma & 6.54 & 5.20 & 7.88 \\
\hline & & Mania & 8.51 & 7.17 & 9.85 \\
\hline & & Agape & 10.31 & 8.97 & 11.65 \\
\hline & \multirow[t]{6}{*}{ Long-term } & Eros & 16.21 & 15.26 & 17.16 \\
\hline & & Ludus & 10.13 & 9.19 & 11.08 \\
\hline & & Storage & 9.48 & 8.53 & 10.42 \\
\hline & & Pragma & 7.55 & 6.61 & 8.50 \\
\hline & & Mania & 9.80 & 8.86 & 10.75 \\
\hline & & Agape & 12.38 & 11.44 & 13.33 \\
\hline & \multirow[t]{6}{*}{ Married } & Eros & 15.28 & 14.74 & 15.81 \\
\hline & & Ludus & 11.24 & 10.70 & 11.77 \\
\hline & & Storage & 8.72 & 8.19 & 9.26 \\
\hline & & Pragma & 7.77 & 7.24 & 8.31 \\
\hline & & Mania & 8.71 & 8.17 & 9.24 \\
\hline & & Agape & 11.66 & 11.12 & 12.20 \\
\hline
\end{tabular}


Table 3 (continued)

\begin{tabular}{|c|c|c|c|c|c|}
\hline \multirow[t]{2}{*}{ Gender } & \multirow[t]{2}{*}{ Relationship status } & \multirow[t]{2}{*}{ LAS-SF subscale } & \multirow[t]{2}{*}{ Mean } & \multicolumn{2}{|c|}{$\begin{array}{l}95 \% \text { Confidence } \\
\text { Interval }\end{array}$} \\
\hline & & & & Lower & Upper \\
\hline \multirow[t]{24}{*}{ Female } & \multirow[t]{6}{*}{ Single } & Eros & 15.60 & 14.74 & 16.46 \\
\hline & & Ludus & 7.92 & 7.06 & 8.78 \\
\hline & & Storage & 9.10 & 8.24 & 9.96 \\
\hline & & Pragma & 8.78 & 7.92 & 9.64 \\
\hline & & Mania & 11.05 & 10.19 & 11.91 \\
\hline & & Agape & 10.78 & 9.92 & 11.64 \\
\hline & \multirow[t]{6}{*}{ Short-term } & Eros & 14.33 & 12.95 & 15.72 \\
\hline & & Ludus & 11.57 & 10.19 & 12.96 \\
\hline & & Storage & 9.33 & 7.95 & 10.72 \\
\hline & & Pragma & 8.51 & 7.12 & 9.89 \\
\hline & & Mania & 10.54 & 9.15 & 11.93 \\
\hline & & Agape & 10.19 & 8.81 & 11.58 \\
\hline & \multirow[t]{6}{*}{ Long-term } & Eros & 17.02 & 16.29 & 17.75 \\
\hline & & Ludus & 7.84 & 7.11 & 8.56 \\
\hline & & Storage & 10.00 & 9.27 & 10.72 \\
\hline & & Pragma & 8.64 & 7.91 & 9.37 \\
\hline & & Mania & 9.79 & 9.06 & 10.52 \\
\hline & & Agape & 11.78 & 11.05 & 12.51 \\
\hline & \multirow[t]{6}{*}{ Married } & Eros & 16.78 & 16.24 & 17.32 \\
\hline & & Ludus & 7.85 & 7.31 & 8.39 \\
\hline & & Storage & 9.44 & 8.90 & 9.98 \\
\hline & & Pragma & 9.05 & 8.51 & 9.59 \\
\hline & & Mania & 8.96 & 8.42 & 9.50 \\
\hline & & Agape & 11.07 & 10.53 & 11.61 \\
\hline
\end{tabular}

In females $\left(\mathrm{F}(3,435)=8.35, p<0.001, \eta_{p}{ }^{2}=0.054\right)$, the Tukey-corrected post-hoc tests revealed that participants in the short-term group reached significantly higher scores than those in the single $(\mathrm{t}(435)=4.35, p<0.001)$, long-term $(\mathrm{t}(435)=4.65$, $p<0.001)$ and married $(\mathrm{t}(435)=4.88, p<0.001)$ groups. See Fig. 2 and Table 3 for descriptive statistics.

The relationship status had a significant main effect on the Eros subscale $(\mathrm{F}(3$, $\left.796)=8.85, p<0.01, \eta_{p}{ }^{2}=0.03\right)$, the Ludus subscale $(\mathrm{F}(3,796)=7.56, p<0.01$, $\left.\eta_{\mathrm{p}}{ }^{2}=0.03\right)$, the Mania subscale $\left(\mathrm{F}(3,796)=7.88, p<0.01, \eta_{p}{ }^{2}=0.03\right)$ and the Agape 


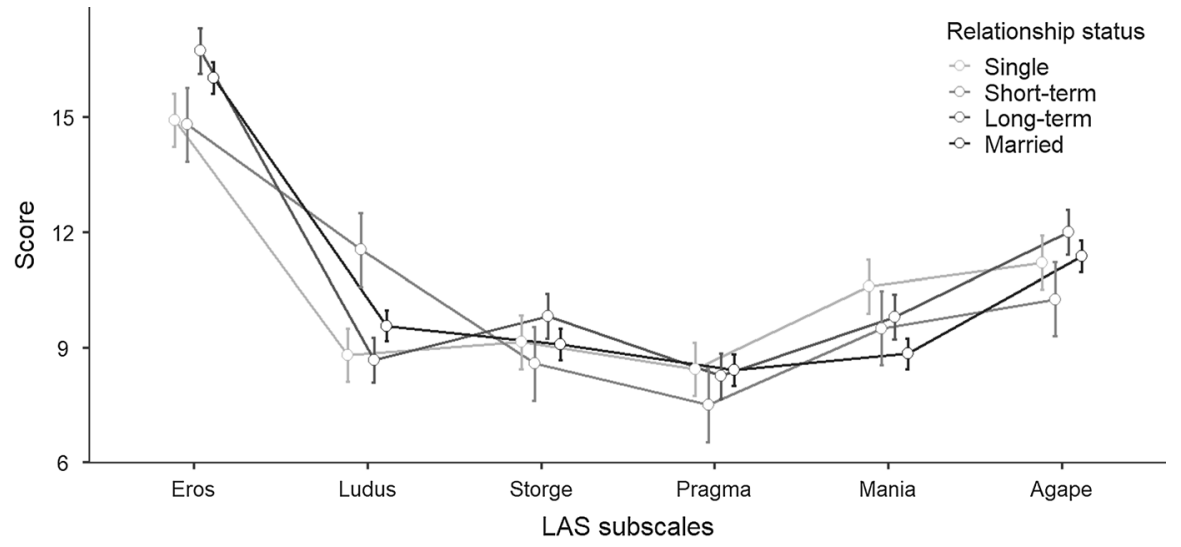

Fig. 3 Relationship status (single, short-term, long-term, married) profiles on the six subscales of the LAS-HSF. Raw scores are presented with $95 \%$ confidence intervals

subscale $\left(\mathrm{F}(3,796)=3.24, p=0.022, \eta_{p}{ }^{2}=0.01\right)$. The Tukey-corrected pairwise comparisons revealed that on the Eros subscale single respondents and people in short-term relationship did not differ but both scored lower than participants in a long-term relationship $(\mathrm{t}(796)=4.44, p<0.01 ; \mathrm{t}(796)=3.74, p<0.01$, respectively) and married $(\mathrm{t}(796)=3.11, p=0.011 ; \mathrm{t}(796)=2.57, p=0.05$, respectively) who did not differ. On the Ludus subscale participants in a short-term relationship scored higher than single $(\mathrm{t}(796)=4.01, p<0.01)$ long-term $(\mathrm{t}(796)=4.44, p<0.01)$ and married $(\mathrm{t}(796)=3.33, p<0.01)$ groups. The latter three groups did not differ from each other. On the Mania subscale married participants scored lower than participants in the single $(\mathrm{t}(796)=4.50, p<0.01)$ and long-term $(\mathrm{t}(796)=2.86, p=0.022)$ group. The other groups did not differ. Lastly, on the Agape subscale the short-term group scored lower than the long-term group $(\mathrm{t}(796)=3.00, p=0.015)$. The other groups did not differ. See Fig. 3 and Table 3 for descriptive data.

\section{Discussion}

The presented results confirmed most predictions of the study, and several novel findings were obtained. The results of the CFA and the reliability analysis show that the LAS-HSF is a reliable measure, whose factor structure is identical with that of the original version (P1). The validity tests revealed a strong negative association between the Eros love style and unrestricted sociosexuality (i.e., the SOI-R scale and its Desire subscale). Furthermore, the Eros love style showed significant but uninterpretably low correlations (rho $<0.25$ ) with mate value (MVS) and various sexual motives (YSEX?-HSF). The Ludus love style showed moderate correlations with the SOI-R and each of its subscales, and with self-focused and coping-oriented sexual motives (personal goal attainment and sex as coping subscales of YSEX-HSF). Apart from these associations, only uninterpretably low correlations were obtained, except for Mania, which showed a relatively high positive correlation with the Sex 
as coping subscale of the YSEX?-HSF. Importantly, no association of an interpretable magnitude was obtained for mate value. This finding contradicts expectation based on a finding reported by Zeigler-Hill and colleagues (2015), who revealed a significant negative relationship between Mania love style and self-esteem. This could be due to the fact that the conceptual overlap between global self-esteem and self-perceived mate value can be moderated by mate choice strategies (mate value in short-term vs. long-term relationship contexts). In sum, the results show that the LAS-HSF is a valid instrument (P2), which provides useful measures for research on love and intimate partner relationships, similarly to the original version and its previously published adaptations.

As expected, preferences for various love styles showed significant differences across relationship statuses. This finding suggests that different types of relationships are typically associated with different types of love experience (see Fig. 3). In other words, relationship type has an impact on partners' feelings of love. This is in line with previous findings (e.g., Dush and Amato 2005; Heshmati et al. 2019; Richardson et al. 1988).

Men as compared to women scored significantly higher on the Ludus love style, while taking account of relationship status provided deeper insight into the connection between sex and love style preferences (see Fig. 2). The related findings show that a significant sex difference in the preference for Ludus may only be observed among singles and among those living in a committed relationship or in marriage, whereas women preferring short-term relationships endorse Ludus as much as their male counterparts. In other words, women pursuing short-term relationship-related goals employ a strategy similar to that followed by men oriented towards the short term (e.g., Buss and Schmitt 1993; Gangestad and Simpson 2000). In such cases, women also prefer game playing to other love styles.

The relative preference for the Eros love style in various relationship statuses showed different patterns among men versus women. Men with casual, committed and married status reported relatively high preference for Eros as compared to single men. Regarding women, by contrast, high Eros scores were only obtained for those living in a committed relationship as opposed to singles and those involved in casual relationships (see Fig. 2). These findings are in line with those obtained in several previous studies. For example, Marzec and Łukasik (2017) suggest that the amount of investment in a relationship is positively associated with commitment. Sex-related qualitative and quantitative differences in investment (e.g., Trivers 1972) are also reflected in men's and women's different love experiences (e.g., Hendrick et al. 1984).

The findings of the present study show that the type of one's love experience is not unrelated to the context of one's relationship and to one's sex. Love style is part of a complex mating strategy, which organizes and orients affective and cognitive functions underlying sexual activity and mate choice, and which in part depends on individual characteristics and on the opportunities of interpersonal contact provided by the social environment. The LAS-HSF questionnaire is presented in Supplement 1. 


\section{Limitations}

While the present study has significant strengths, including the verification of the factor structure and validity of the LAS-HSF, certain limitations are also worth noting. The study failed to assess participants' sexual orientation, while individuals with different orientations may show essential differences in love experience (e.g., Rosenberger et al. 2014; Unrau and Morry 2019). This is a shortcoming that future studies on love, sexuality and intimate partner relationships should eliminate.

Although the present study laid particular emphasis on relationship status both in the underlying theoretical considerations and in the interpretation of the findings, only one item with four response alternatives was dedicated to the assessment of participants' relationship status. It would have been possible to assess the duration of, satisfaction with, and the quality of attachment and commitment in, participants' relationships, as these variables have been commonly assessed in related studies (e.g., Ahmetoglu et al. 2010; Cannas Aghedu et al. 2020). Future studies should include a more thorough and more complex assessment of participants' relationship status.

Importantly, the associations between love styles and relationship statuses may be influenced by several factors not examined in the present study. The obtained findings support Lee's original theory suggesting that the love experienced in different types of relationships may have diverse bases, since different types of relationships involve individuals with different personality structures, attachment styles, and sociosexual orientations, who follow different mate choice strategies (Lee 1973, 1988).

Finally, the mean differences obtained in the present study showed relatively low, albeit significant, effect sizes. Consequently, these findings have limited validity, and further studies are required in order to draw reliable general conclusions.

Supplementary Information The online version contains supplementary material available at (https://doi. org/10.1007/s12119-021-09830-z).

Funding Open access funding provided by University of Pécs.. The project has been supported by the European Union and co-financed by the European Social Fund (EFOP-3.6.1.-16-2016-00004-Comprehensive Development for Implementing Smart Specialization Strategies at the University of Pécs).

\section{Compliance with Ethical Standards}

Conflict of interest Author Norbert Meskó declares that he has no conflict of interest. Author András N. Zsidó declares that he has no conflict of interest. Author András Láng declares that he has no conflict of interest. Author Kázmér Karádi declares that he has no conflict of interest.

Ethical Approval All procedures performed in studies involving human participants were in accordance with the ethical standards of the institutional and/or national research committee and with the $1964 \mathrm{Hel}-$ sinki declaration and its later amendments or comparable ethical standards.

Informed Consent Informed consent was obtained from all individual participants included in the study. 
Open Access This article is licensed under a Creative Commons Attribution 4.0 International License, which permits use, sharing, adaptation, distribution and reproduction in any medium or format, as long as you give appropriate credit to the original author(s) and the source, provide a link to the Creative Commons licence, and indicate if changes were made. The images or other third party material in this article are included in the article's Creative Commons licence, unless indicated otherwise in a credit line to the material. If material is not included in the article's Creative Commons licence and your intended use is not permitted by statutory regulation or exceeds the permitted use, you will need to obtain permission directly from the copyright holder. To view a copy of this licence, visit http://creativecommons.org/licen ses/by/4.0/.

\section{References}

Agus, M., Puddu, L., Gonnelli, C., \& Raffagnino, R. (2018). Love Attitudes Scale Short Form: The Preliminary Assessment of the Factor Structure of Its Italian Version. Applied Psychology Bulletin, 66, 15-31. https://doi.org/10.26387/bpa.282.2.

Ahmetoglu, G., Swami, V., \& Chamorro-Premuzic, T. (2010). The relationship between dimensions of love, personality, and relationship length. Archives of Sexual Behavior, 39(5), 1181-1190. https ://doi.org/10.1007/s10508-009-9515-5.

Armstrong, H. L., \& Reissing, E. D. (2015). Women's motivations to have sex in casual and committed relationships with male and female partners. Archives of Sexual Behavior, 44(4), 921-934. https://doi.org/10.1007/s10508-014-0462.

Bailey, W. C., Hendrick, C., \& Hendrick, S. S. (1987). Relation of sex and gender role to love, sexual attitudes, and self-esteem. Sex Roles, 16(11-12), 637-648. https://doi.org/10.1007/BF00300378.

Baker, F. B. (2001). The Basics of Item Response Theory (2nd ed.). College Park, MD: ERIC Clearinghouse on Assessment and Evaluation.

Belsky, J., Steinberg, L., \& Draper, P. (1991). Childhood experience, interpersonal development, and reproductive strategy: An evolutionary theory of socialization. Child Development, 62(4), 647670. https://doi.org/10.1111/j.1467-8624.1991.tb01558.x.

Bjorklund, D. F., \& Ellis, B. J. (2014). Children, childhood, and development in evolutionary perspective. Developmental Review, 34, 225-264. https://doi.org/10.1016/j.dr.2014.05.005.

Brislin, R. W. (1980). Translation and content analysis of oral and written material. In H. C. Triandis \& J. W. Berry (Eds.), Handbook of Cross-Cultural Psychology: Methodology (pp. 389-444). Boston: Allyn and Bacon.

Bugay, A., \& Tezer, E. (2008, March). Attachment styles and loving attitudes among Turkish university students. Paper presented at the 2nd Annual Global Conference: Persons, Intimacy and Love. pp. 10-13 March, Salzburg, Austria.

Buss, D. M. (1989). Sex differences in human mate preferences: Evolutionary hypotheses tested in 37 cultures. Behavioral and Brain Sciences, 12(1), 1-14. https://doi.org/10.1017/S0140525X0 0023992.

Buss, D. M. (2006). Strategies of human mating. Psychological Topics, 15(2), 239-260.

Buss, D. M., \& Schmitt, D. P. (1993). Sexual strategies theory: an evolutionary perspective on human mating. Psychological Review, 100(2), 204-232. https://doi.org/10.1037/0033-295X.100.2.204.

Buss, D. M., \& Schmitt, D. P. (2019). Mate preferences and their behavioral manifestations. Annual Review of Psychology, 70, 77-110. https://doi.org/10.1146/annurev-psych-010418-103408.

Cannas Aghedu, F., Veneziani, C. A., Manari, T., Feybesse, C., \& Bisiacchi, P. S. (2020). Assessing passionate love: Italian validation of the PLS (reduced version). Sexual and Relationship Therapy, 35(1), 77-88. https://doi.org/10.1080/14681994.2018.1442570.

Clark, R. D., \& Hatfield, E. (1989). Gender differences in receptivity to sexual offers. Journal of Psychology \& Human Sexuality, 2(1), 39-55. https://doi.org/10.1300/J056v02n01_04.

Conroy-Beam, D., Roney, J. R., Lukaszewski, A. W., Buss, D. M., Asao, K., Sorokowska, A., \& Alm, C. (2019). Assortative mating and the evolution of desirability covariation. Evolution and Human Behavior., 40(5), 479-491. https://doi.org/10.1016/j.evolhumbehav.2019.06.003. 
Csajbók, Z., Havlíček, J., Demetrovics, Z., \& Berkics, M. (2019). Self-Perceived Mate Value Is Poorly Predicted by Demographic Variables. Evolutionary Psychology. https://doi.org/10.1177/14747 04919829037.

Csathó, Á., \& Birkás, B. (2018). Early-life stressors, personality development, and fast life strategies: An evolutionary perspective on malevolent personality features. Frontiers in Psychology, 9, 305. https://doi.org/10.3389/fpsyg.2018.00305.

Davies, M. F. (1996). EPQ correlates of love styles. Personality and Individual Differences, 20(2), 257-259. https://doi.org/10.1016/0191-8869(95)00188-3.

Del Giudice, M., Gangestad, S. W., \& Kaplan, H. S. (2015). Life history theory and evolutionary psychology. In D. M. Buss (Ed.), The handbook of evolutionary psychology (2nd ed., pp. 88-114). New York: Wiley.

Dush, C. M. K., \& Amato, P. R. (2005). Consequences of relationship status and quality for subjective well-being. Journal of Social and Personal Relationships, 22, 607-627. https://doi. org/10.1177/0265407505056438.

Eagly, A. H., \& Wood, W. (1999). The origins of sex differences in human behavior: Evolved dispositions versus social roles. American Psychologist, 54(6), 408-423. https://doi. org/10.1037/0003-066X.54.6.408.

Edlund, J. E., \& Sagarin, B. J. (2014). The mate value scale. Personality and Individual Differences, 64, 72-77. https://doi.org/10.1016/j.paid.2014.02.005.

Ellis, B. J. (1992). The evolution of sexual attraction: Evaluative mechanisms in women. In J. H. Barkow, L. Cosmides, \& J. Tooby (Eds.), The adapted mind: Evolutionary psychology and the generation of culture (pp. 267-288). New York, NY: Oxford University Press.

Ellis, B. J., Figueredo, A. J., Brumbach, B. H., \& Schlomer, G. L. (2009). Fundamental dimensions of environmental risk. Human Nature, 20(2), 204-268. https://doi.org/10.1007/s12110-009-9063-7.

Emanuele, E., Brondino, N., Pesenti, S., Re, S., \& Geroldi, D. (2007). Genetic loading on human loving styles. Neuroendocrinology Letters, 28(6), 815-821.

Fawcett, T. W., \& Johnstone, R. A. (2003). Mate choice in the face of costly competition. Behavioral Ecology, 14(6), 771-779. https://doi.org/10.1093/beheco/arg075.

Field, A. (2000). Discovering statistics using SPSS for Windows. London-Thousand Oaks- New Delhi: Sage Publications.

Field, A. (2009). Discovering statistics using SPSS. London: SAGE.

Fletcher, G. J. O., Simpson, J. A., Thomas, G., \& Giles, L. (1999). Ideals in intimate relationships. Journal of Personality and Social Psychology, 76(1), 72-89. https://doi.org/10.1037/0022-3514.76.1.72.

Frey, K., \& Hojjat, M. (1998). Are love styles related to sexual styles? Journal of Sex Research, 35(3), 265-271. https://doi.org/10.1080/00224499809551942.

Gana, K., Saada, Y., \& Untas, A. (2013). Effects of love styles on marital satisfaction in heterosexual couples: A dyadic approach. Marriage and Family Review, 49(8), 754-772. https://doi. org/10.1080/01494929.2013.834025.

Gangestad, S. W., \& Simpson, J. A. (2000). The evolution of human mating: Trade-offs and strategic pluralism. Behavioral and Brain Sciences, 23(4), 573-587. https://doi.org/10.1017/S0140525X000033 $7 \mathrm{X}$.

Gillen, M. M., Collisson, B., Murtagh, M., Browne, B. L., \& McCutcheon, L. E. (2016). Additional psychometric data for the mate value scale. Journal of Relationships Research. https://doi.org/10.1017/ jrr.2016.7.

Gravetter, F., \& Wallnau, L. (2014). Essentials of statistics for the behavioral sciences (8th ed.). Belmont, CA: Wadsworth.

Griskevicius, V., Tybur, J. M., Delton, A. W., \& Robertson, T. E. (2011). The influence of mortality and socioeconomic status on risk and delayed rewards: a life history theory approach. Journal of Personality and Social Psychology, 100(6), 1015-1026. https://doi.org/10.1037/a0022403.

Hadden, B. W., Harvey, S. M., Settersten, R. A., Jr., \& Agnew, C. R. (2019). What do I call us? The investment model of commitment processes and changes in relationship categorization. Social Psychological and Personality Science, 10(2), 235-243. https://doi.org/10.1177/1948550617745115.

Hallam, L., De Backer, C. J., Fisher, M. L., \& Walrave, M. (2018). Are sex differences in mating strategies overrated? Sociosexual orientation as a dominant predictor in online dating strategies. Evolutionary Psychological Science, 4(4), 456-465. https://doi.org/10.1007/s40806-018-0150-z.

Hammock, G., \& Richardson, D. S. (2011). Love attitudes and relationship experience. The Journal of Social Psychology, 151(5), 608-624. https://doi.org/10.1080/00224545.2010.522618. 
Hatfield, E. C., Luckhurst, C., \& Rapson, R. L. (2012). A brief history of attempts to measure sexual motives. Interpersona: An International Journal on Personal Relationships, 6(2), 138-154.

Hendrick, C., \& Hendrick, S. (1986). A theory and method of love. Journal of Personality and Social Psychology, 50(2), 392-402. https://doi.org/10.1037/0022-3514.50.2.392.

Hendrick, C., \& Hendrick, S. (1995). Gender differences and similarities in sex and love. Personal Relationships, 2, 55-65. https://doi.org/10.1111/j.1475-6811.1995.tb00077.x.

Hendrick, C., \& Hendrick, S. S. (1990). A relationship-specific version of the Love Attitudes Scale. Journal of Social Behavior and Personality, 5(4), 239-254.

Hendrick, C., \& Hendrick, S. S. (2006). Styles of romantic love. In R. J. Sternberg \& K. Weis (Eds.), The new psychology of love (2nd ed., pp. 149-170). New Haven, CT: Yale University Press.

Hendrick, C., Hendrick, S. S., \& Dicke, A. (1998). The love attitudes scale: Short form. Journal of Social and Personal Relationships, 15(2), 147-159. https://doi.org/10.1177/0265407598152001.

Hendrick, C., Hendrick, S., Foote, F. H., \& Slapion-Foote, M. J. (1984). Do men and women love differently? Journal of Social and Personal Relationships, 1(2), 177-195. https://doi.org/10.1177/02654 07584012003.

Hendrick, S. S. (1988). A generic measure of relationship satisfaction. Journal of Marriage and the Family, 50, 93-98.

Hendrick, S. S., Hendrick, C., \& Adler, N. L. (1988). Romantic relationships: Love, satisfaction, and staying together. Journal of Personality and Social Psychology, 54(6), 980-988.

Heshmati, S., Oravecz, Z., Pressman, S., Batchelder, W. H., Muth, C., \& Vandekerckhove, J. (2019). What does it mean to feel loved: Cultural consensus and individual differences in felt love. Journal of Social and Personal Relationships, 36(1), 214-243. https://doi.org/10.1177/0265407517724600.

Howie, J. M., \& Pomiankowski, A. (2018). Mate Value. In T. Shackelford \& V. Weekes-Shackelford (Eds.), Encyclopedia of Evolutionary Psychological Science. Cham: Springer.

Jonason, P. K., \& Kavanagh, P. (2010). The dark side of love: Love styles and the Dark Triad. Personality and Individual Differences, 49(6), 606-610. https://doi.org/10.1016/j.paid.2010.05.030.

Jonason, P. K., Zeigler-Hill, V., \& Hashmani, T. (2019). Love, Sex, and Personality Pathology: A Life History View of Personality Pathologies and Sociosexuality. The Journal of Sex Research, 56(2), 239-248. https://doi.org/10.1080/00224499.2018.1471444.

Kaplan, H. S., \& Gangestad, S. W. (2005). Life history theory and evolutionary psychology. In D. M. Buss (Ed.), Handbook of evolutionary psychology (pp. 68-95). New York, NY: Wiley.

Kennair, L. E. O., Wyckoff, J. P., Asao, K., Buss, D. M., \& Bendixen, M. (2018). Why do women regret casual sex more than men do? Personality and Individual Differences, 127, 61-67. https://doi. org/10.1016/j.paid.2018.01.044.

Kirsner, B. R., Figueredo, A. J., \& Jacobs, W. J. (2003). Self, friends, and lovers: Structural relations among Beck Depression Inventory scores and perceived mate values. Journal of Affective Disorders, 75(2), 131-148. https://doi.org/10.1016/S0165-0327(02)00048-4.

Lacey, R. S., Reifman, A., Scott, J. P., Harris, S. M., \& Fitzpatrick, J. (2004). Sexual-moral attitudes, love styles, and mate selection. Journal of Sex Research, 41(2), 121-128. https://doi.org/10.1080/00224 490409552220.

Laswell, T. E., \& Laswell, M. E. (1976). I love you but I'm not in love with you. Journal of Marriage and Family Counseling, 38, 211-224. https://doi.org/10.1111/j.1752-0606.1976.tb00413.x.

Lee, J. A. (1973). The colors of love: An exploration of the ways of loving. Toronto, Ontario, Canada: New Press.

Lee, J. A. (1988). Love-styles. In R. J. Sternberg \& M. Barnes (Eds.), The psychology of love (pp. 38-67.). New Haven, CT: Yale University Press.

Lee, K., Ashton, M. C., Wiltshire, J., Bourdage, J. S., Visser, B. A., \& Gallucci, A. (2013). Sex, power, and money: Prediction from the Dark Triad and Honesty-Humility. European Journal of Personality, 27(2), 169-184. https://doi.org/10.1002/per.1860.

Lippa, R. A. (2009). Sex differences in sex drive, sociosexuality, and height across 53 nations: Testing evolutionary and social structural theories. Archives of Sexual Behavior, 38(5), 631-651. https://doi. org/10.1007/s10508-007-9242-8.

Marzec, M., \& Łukasik, A. (2017). Love Styles in the Context of Life History Theory. Polish Psychological Bulletin, 48(2), 237-249. https://doi.org/10.1515/ppb-2017-0027.

Meskó, N., Láng, A., \& Kocsor, F. (2014). The Hungarian Version of Sociosexual Orientation Inventory Revised (SOI-R): Sex and Age Differences. Interpersona, 8(1), 85-99. https://doi.org/10.5964/ijpr. v8i1.130. 
Meskó, N., Szatmári, D., Láng, A., Meston, C. M. \& Buss, D. M. (2019). Why Hungarians Have Sex (YSEX-HSF). Manuscript submitted for publication.

Meston, C. M., \& Buss, D. M. (2007). Why humans have sex. Archives of Sexual Behavior, 36(4), 477507. https://doi.org/10.1007/s10508-007-9175-2.

Meston, C. M., \& Stanton, A. M. (2017). Recent findings on women's motives for engaging in sexual activity. Current Sexual Health Reports, 9(3), 128-135. https://doi.org/10.1007/s11930-017-0114-5.

Meston, C. M., Hamilton, L. D., \& Harte, C. B. (2009). Sexual motivation in women as a function of age. The Journal of Sexual Medicine, 6(12), 3305-3319. https://doi.org/10.1111/j.1743-6109.2009.01489 .x.

Meston, C. M., Kilimnik, C. D., Freihart, B. K., \& Buss, D. M. (2019). Why Humans Have Sex: Development and Psychometric Assessment of a Short-Form Version of the YSEX? Instrument. Journal of Sex and Marital Therapy. https://doi.org/10.1080/0092623X.2019.1654581.

Morrow, G. D., Clark, E. M., \& Brock, K. F. (1995). Individual and partner love styles: Implications for the quality of romantic involvements. Journal of Social and Personal Relationships, 12(3), 363387. https://doi.org/10.1177/0265407595123003.

Naftolin, F. (1981). Understanding the bases of sex differences. Science, 211, 1263-1264. https://doi. org/10.1126/science.7209509.

Neto, F. (1993). Love styles and self-representations. Personality and Individual Differences, 14, 795803. https://doi.org/10.1016/0191-8869(93)90092-H.

Neto, F. (2015). Revisiting correlates of sociosexuality for men and women: The role of love relationships and psychological maladjustment. Personality and Individual Differences, 83, 106-110. https://doi. org/10.1016/j.paid.2015.03.033.

Neto, F., Mullet, E., Deschamps, J. C., Barros, J., Benvindo, R., Camino, L., \& Machado, M. (2000). Cross-cultural variations in attitudes toward love. Journal of Cross-Cultural Psychology, 31(5), 626-635. https://doi.org/10.1177/0022022100031005005.

Nettle, D. (2010). Dying young and living fast: Variation in life history across English neighborhoods. Behavioral Ecology, 21(2), 387-395. https://doi.org/10.1093/beheco/arp202.

Ohno, S. (1967). Sex Chromosomes and Sex-linked Genes. N.Y.: Springer-Verlag.

Penke, L., \& Asendorpf, J. B. (2008). Beyond global sociosexual orientations: a more differentiated look at sociosexuality and its effects on courtship and romantic relationships. Journal of Personality and Social Psychology, 95(5), 1113-1135. https://doi.org/10.1037/0022-3514.95.5.1113.

Proyer, R. T., Brauer, K., Wolf, A., \& Chick, G. (2018). Beyond the Ludic Lover: Individual Differences in Playfulness and Love Styles in Heterosexual Relationships. American Journal of Play, 10(3), 265-289.

Raffagnino, R., \& Puddu, L. (2018). Love Styles in Couple Relationships: A Literature Review. Open Journal of Social Sciences, 6(12), 307-330. https://doi.org/10.4236/jss.2018.612027.

Rhodes, G., Simmons, L. W., \& Peters, M. (2005). Attractiveness and sexual behavior: Does attractiveness enhance mating success? Evolution and Human Behavior, 26(2), 186-201. https://doi. org/10.1016/j.evolhumbehav.2004.08.014.

Richardson, D. R., Medvin, N., \& Hammock, G. (1988). Love styles, relationship experience, and sensation seeking: A test of validity. Personality and Individual Differences, 9(3), 645-651. https://doi. org/10.1016/0191-8869(88)90161-4.

Rodrigues, D., \& Lopes, D. (2017). Sociosexuality, commitment, and sexual desire for an attractive person. Archives of Sexual Behavior, 46(3), 775-788. https://doi.org/10.1007/s10508-016-0814-3.

Rosenberger, J. G., Herbenick, D., Novak, D. S., \& Reece, M. (2014). What's love got to do with it? Examinations of emotional perceptions and sexual behaviors among gay and bisexual men in the United States. Archives of Sexual Behavior, 43(1), 119-128. https://doi.org/10.1007/s1050 8-013-0223-9.

Rotzien, A., Vacha-Haase, T., Murthy, K., Davenport, D., \& Thompson, B. (1994). A confirmatory factor analysis of the hendrick-hendrick love attitudes scale: We may not yet have an acceptable model. Structural Equation Modeling: A Multidisciplinary Journal, 1(4), 360-374. https://doi. org/10.1080/10705519409539985.

Samejima, F. (1968). Estimation of Latent Ability Using a Response Pattern of Graded Scores. ETS Research Bulletin Series, 1968(1), 1-169. https://doi.org/10.1002/j.2333-8504.1968.tb00153.x.

Smith, C. V., Øverup, C. S., \& Webster, G. D. (2019). Sexy deeds done dark? Examining the relationship between dark personality traits and sexual motivation. Personality and Individual Differences, 146, 105-110. https://doi.org/10.1016/j.paid.2019.04.003. 
The jamovi project (2020). jamovi (Version 1.2) [Computer Software]. Retrieved from https://www. jamovi.org

Thornhill, R., \& Gangestad, S. W. (1994). Human fluctuating asymmetry and sexual behavior. Psychological Science, 5(5), 297-302. https://doi.org/10.1111/j.1467-9280.1994.tb00629.x.

Trivers, R. (1972). Parental investment and sexual selection. In B. Campbell (Ed.), Sexual selection and the descent of man (pp. 1871-1971). Chicago, IL: Aldine.

Trochim, W. M., \& Donnelly, J. P. (2006). The research methods knowledge base (3rd ed.). Cincinnati, $\mathrm{OH}$ : Atomic Dog.

Unrau, A. M., \& Morry, M. M. (2019). The subclinical psychopath in love: mediating effects of attachment styles. Journal of Social and Personal Relationships, 36(2), 421-449. https://doi. org/10.1080/00224499.2019.1671949.

Valentova, J. V., Junior, F. P. M., Štěrbová, Z., Varella, M. A. C., \& Fisher, M. L. (2020). The association between Dark Triad traits and sociosexuality with mating and parenting efforts: A crosscultural study. Personality and Individual Differences, 154, 109613. https://doi.org/10.1016/j. paid.2019.109613.

Walsh, A. (1993). Love styles, masculinity/femininity, physical attractiveness, and sexual behavior: A test of evolutionary theory. Ethology and Sociobiology, 14(1), 25-38. https://doi.org/10.1016/01623095(93)90015-A.

Walter, K. V., Conroy-Beam, D., Buss, D. M., Asao, K., Sorokowska, A., Sorokowski, P., \& Zupančič, M. (2020). Sex Differences in Mate Preferences Across 45 Countries: A Large-Scale Replication. Psychological Science. https://doi.org/10.1177/0956797620904154.

Wan Shahrazad, W. S., Hoesni, S. M., \& Chong, S. T. (2012). Investigating the factor structure of the Love Attitude Scale (LAS) with Malaysian samples. Asian Social Science, 8(9), 66-73. https://doi. org/10.5539/ass.v8n9p66.

White, J. K., Hendrick, S. S., \& Hendrick, C. (2004). Big personality variables and relationship constructs. Personality and Individual Differences, 37(7), 1519-1530. https://doi.org/10.1016/j. paid.2004.02.019.

Yang, Y., \& Liu, A. (2007). Reliability and Validity of the Chinese Love Attitude Scale. Asian Social Science, 3(8), 41-44.

Zeigler-Hill, V., Britton, M., Holden, C. J., \& Besser, A. (2015). How will I love you? Self-esteem instability moderates the association between self-esteem level and romantic love styles. Self and Identity, 14(1), 118-134. https://doi.org/10.1080/15298868.2014.960445.

Publisher's Note Springer Nature remains neutral with regard to jurisdictional claims in published maps and institutional affiliations. 